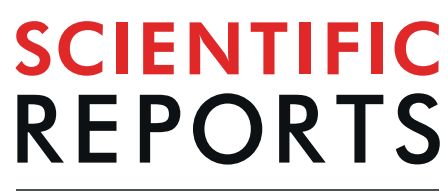

natureresearch

Received: 10 May 2019

Accepted: 18 September 2019

Published online: 07 October 2019

\title{
Microsporidia Nosema spp. - obligate bee parasites are transmitted by air
}

\author{
Aneta Sulborska ${ }^{1}$, Beata Horecka ${ }^{2}$, Malgorzata Cebrat ${ }^{3}$, Marek Kowalczyk ${ }^{2}$, \\ Tomasz H. Skrzypek ${ }^{4}$, Waldemar Kazimierczak ${ }^{5}$, Mariusz Trytek ${ }^{6}$ \& Grzegorz Borsuk ${ }^{2}$
}

Microsporidia Nosema are transferred among bees via the faecal-oral route. Nosema spp. spores have been detected on flowers and transferred to hives along with the bee pollen. The aim of the present study was to determine whether Nosema microsporidia are transferred by air in an apiary, in a control area (without the presence of bee colonies), and/or in a laboratory during cage experiments with artificially infected bees. The novel way of transmission by air was investigated by the volumetric method using a Hirst-type aerobiological sampler located on the ground in the apiary, in the Botanical Garden and on the laboratory floor. Concurrently, the mean rate of Nosema infections in the foragers in the apiary was estimated with the Bürker haemocytometer method. Spore-trapping tapes were imaged by means of light microscopy, Nomarski interference contrast microscopy and scanning electron microscopy. The highest concentration of Nosema spores per $1 \mathrm{~m}^{3}$ of air (4.65) was recorded in August, while the lowest concentration (2.89) was noted in July. This was confirmed by a Real-Time PCR analysis. The presence of $N$. apis as well as $N$. ceranae was detected in each of the tested tapes from the apiary. The average copy number of $N$. apis was estimated at $14.4 \times 10^{4}$ copies per $1 \mathrm{~cm}^{2}$ of the tape; whereas the number of $N$. ceranae was $2.24 \times 10^{4}$ copies per tape per $1 \mathrm{~cm}^{2}$. The results indicate that Nosema microsporidia were transferred by the wind in the apiary, but not in the Botanical Garden and laboratory by air. This was confirmed by genetic analyses. DNA from immobilised biological material was isolated and subjected to a PCR to detect the Nosema species. A fragment of the 16S rRNA gene, characteristic of Nosema apis and $N$. ceranae, was detected. Our research adds knowledge about the transfer of Nosema spp. microsporidia in the natural environment and indicates the season associated with the greatest risk of a bee colony infection with Nosema spp.

Microsporidia are ubiquitous in the environment and they infect almost all invertebrates and vertebrates ${ }^{1}$. The phylum Microsporidia is a large group of eukaryotic obligate intracellular parasites that can only complete their life cycle within an infected eukaryotic host cell ${ }^{2}$. Despite mitochondria that are reduced to mitosomes and a lack of some other organelles in the cell structure, microsporidia are acknowledged as belonging to the kingdom of Fungi ${ }^{3,4}$. Nosema apis ${ }^{5}$ and Nosema ceranae ${ }^{6}$ microsporidia are parasites of adult bees that are causing severe losses worldwide ${ }^{7}$. N. apis spores are 4-6 $\times 2-4 \mu \mathrm{m}$ and $N$. ceranae spores are 3.3-5.5 $\times 2.3-3.0 \mu \mathrm{m}$ in size $\mathrm{e}^{6,8}$. The largest $N$. ceranae spores occupy a size range similar to that of the smaller N. apis spores ${ }^{9}$. Microsporidia are typically transmitted horizontally via the faecal-oral route, and an infection can occur, for example, by the ingestion

${ }^{1}$ Department of Botany, University of Life Sciences, Akademicka 15, 20-950, Lublin, Poland. ${ }^{2}$ Institute of Biological Basis of Animal Production; Faculty of Animal Sciences and Bioeconomy, University of Life Sciences in Lublin, Akademicka 13, 20-950, Lublin, Poland. ${ }^{3}$ Laboratory of Molecular and Cellular Immunology, Hirszfeld Institute of Immunology and Experimental Therapy, Polish Academy of Sciences, Weigla 12, 53-114, Wroclaw, Poland. ${ }^{4}$ Laboratory of Confocal and Electron Microscopy, Department of Biotechnology and Environment Sciences Centre for Interdisciplinary Research, John Paul II Catholic University of Lublin, Al. Kraśnicka 102, 29-718, Lublin, Poland. ${ }^{5}$ Faculty of Biotechnology and Environmental Sciences, Centre for Interdisciplinary Research, Laboratory of Biocontrol, Production and Application of EPN, John Paul II Catholic University of Lublin, Konstantynów 1J, 20 708, Lublin, Poland. ${ }^{6}$ Department of Industrial Microbiology, Institute of Microbiology and Biotechnology, Faculty of Biology and Biotechnology, Maria Curie-Skłodowska University, Akademicka 19, 20-033, Lublin, Poland. Aneta Sulborska, Mariusz Trytek and Grzegorz Borsuk contributed equally. Correspondence and requests for materials should be addressed to G.B. (email: grzegorz.borsuk@up.lublin.pl) 


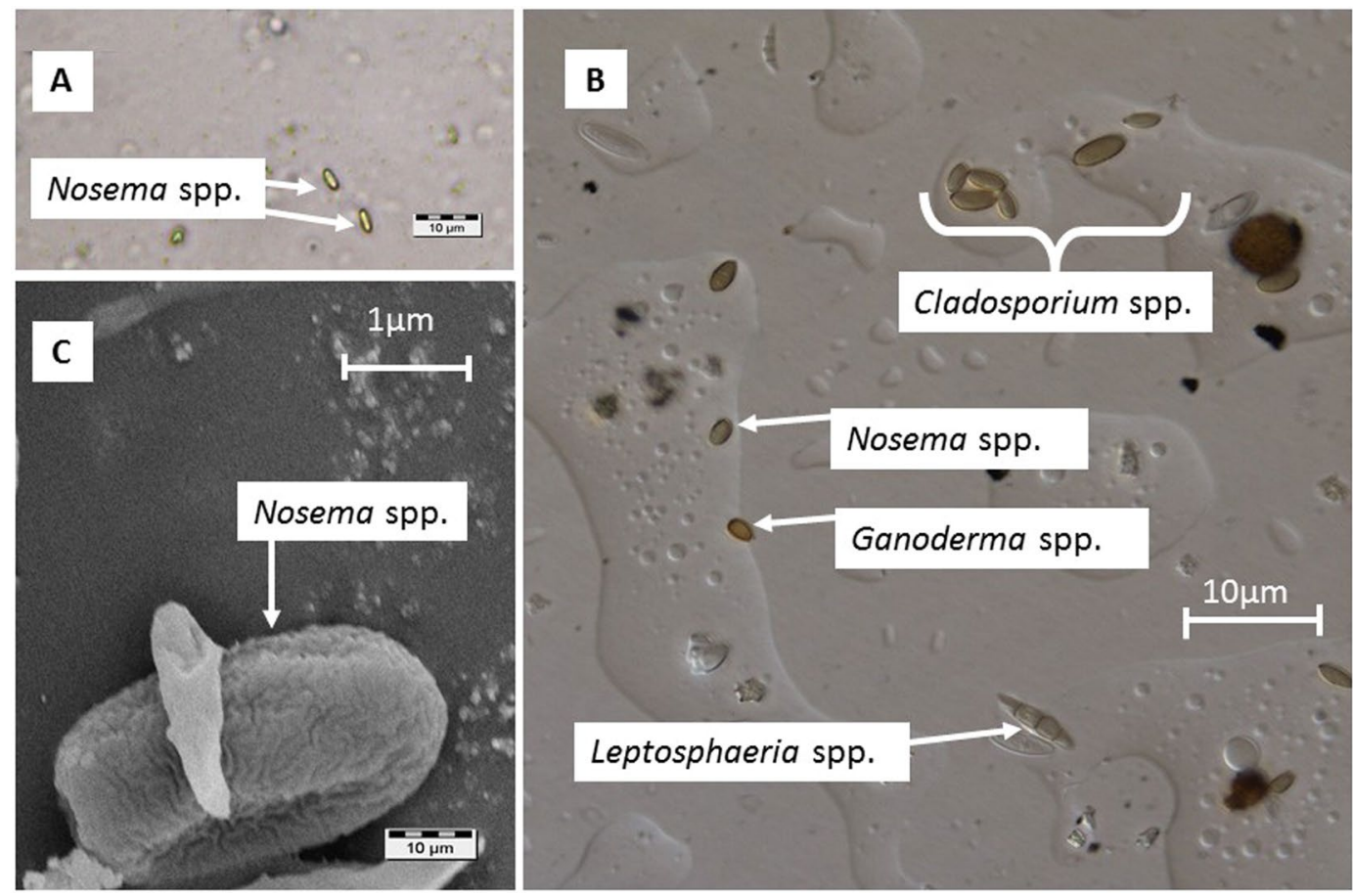

Figure 1. Microscope image. (A) Light microscope image of Nosema spp. spores on the tape. (B) Nomarski interference contrast microscope image of spores on the tape. (C) Nosema spp. spores on the tape visible under a scanning electron microscope.

of spores in feed via trophallaxis in the nest ${ }^{10,11}$. Sokół and Michalczyk ${ }^{12}$ found Nosema microsporidia in bee pollen and bee bread. However, during grooming of the body hairs ${ }^{13-15}$ and the formation of bee pollen, bees add droplets of nectar from the crop, which may contain these spores, to facilitate the gluing of pollen grains. In a honeybee colony, the foragers are potentially more likely to be exposed to infection than the hive workers ${ }^{16-21}$. Beshers et al. ${ }^{22}$ assumed that all foragers are older than any of the hive workers, and they are more infected by the microsporidia Nosema ${ }^{18}$. Nosema spores can also be transmitted indirectly via shared food sources or by the robbery of contaminated products ${ }^{23-25}$.

Infected Lepidoptera, namely the Galleria mellonella larvae which live in the hives, may disseminate the pathogen between colonies ${ }^{26}$. The transmission of Nosema may also be facilitated by Merops apiaster ${ }^{27,28}$ and Loxostege sticticalis adults which feed on flowers and may facilitate large-scale dispersals of the pathogen due to a high migratory activity ${ }^{29}$.

Previous research on $N$. ceranae infections and the deformed wing virus in wild bumblebee species ${ }^{30-35}$ has provided a basis for investigations of new routes for the spreading of pathogens that infect pollinating insects. Durrer and Schmid-Hempe ${ }^{36}$ have shown that shared flowers can lead to the horizontal transmission of Crithidia bombi among bumblebee colonies. This may be due to the risk of infection both in the nest and on the flowers, where the bumblebees leave their excrement while looking for nectar ${ }^{36-38}$. The similarity in the size of Crithidia bombi and Nosema suggests the same route of transmission for these parasites. Indeed, Graystock et al. ${ }^{39}$ identified N. ceranae in flowers. Nosema spores have also been found in bee pollen ${ }^{12}$. These findings prompted us to investigate the possibility of Nosema transmission in the air. The aim of the present study was to determine whether Nosema microsporidia are transferred by air in an apiary, in a Botanical Garden (BG; with no bee colonies), and/or in a laboratory during cage experiments with artificially infected bees.

\section{Results and Discussion}

During the spore collection that occurred at the beginning of the experiment, the prevalence of uninfected colonies was $84 \%$; whereas this value at the end of the experiment was $76 \%$. The mean number of Nosema spp. per forager in the infected colonies increased from $7.4 \times 10^{6}$ in June to $28.6 \times 10^{6}$ in August $\left(\mathrm{F}_{(29)}=22.96 ; \mathrm{p}=0.000014\right)$.

The biological material, which was collected in parallel between June 1 and September 1 from the apiary air and immobilised on the sampler tapes, was analysed. Photographs were taken during the microscopic analyses of Nosema spp. observed with light (Fig. 1A) and with Nomarski interference contrast (Fig. 1B) microscopy. The Nosema spores were counted under the light microscope, as this was the easiest way to identify the spores on the collected tapes (Fig. 1A). Single or clustered Nosema spores were identified on the tapes among typical airborne fungi, such as Ganoderma spp., Leptosphaeria spp. and Cladosporium spp. (Fig. 1B). The highest concentration of Nosema spores per $1 \mathrm{~m}^{3}$ of air (4.65) was recorded in August, while the lowest concentration (2.89) was noted in July $\left(\mathrm{F}_{(6)}=11.75 ; \mathrm{p}=0.029\right)$ (Table 1$)$. There were no Nosema spores on the Hirst-type sampler tapes collected in the $\mathrm{BG}$ and in the laboratory (Table 1 ). 


\begin{tabular}{|l|l|l|l|}
\hline Location & \multicolumn{3}{|l|}{ Time Period } \\
\hline \multirow{2}{*}{ Apiary } & June & July & August \\
\cline { 2 - 4 } & $3.45 \pm 0.55^{\text {ab }}$ & $2.89 \pm 0.11^{\mathrm{a}}$ & $4.65 \pm 0.35^{\mathrm{b}}$ \\
\hline Botanical Garden & $0.00 \pm 0.00$ & $0.00 \pm 0.00$ & $0.00 \pm 0.00$ \\
\hline \multirow{2}{*}{ Laboratory } & Week 1 & Week $\mathbf{2}$ & Week 3 \\
\cline { 2 - 4 } & $0.00 \pm 0.00$ & $0.00 \pm 0.00$ & $0.00 \pm 0.00$ \\
\hline
\end{tabular}

Table 1. Mean number of Nosema spp. in $1 \mathrm{~m}^{3}$ of air. \pm - standard deviation. a,b - the different small letters denote statistically significant differences between the number of Nosema spores in the month (one-way ANOVA, $\mathrm{F}_{(6)}=11.75, \mathrm{p}=0.029$; Tukey test, $\left.\mathrm{p} \leq 0.05\right)$.

Although microscopic analyses are sufficient methods for the identification of spores in aerobiological studies, they would not provide conclusive scientific evidence in the present investigations due to the low morphological diversity of the Nosema spores. Therefore, we carried out an analysis of the spore-trapping tapes by a scanning electron microscopy, which showed the characteristic shape and sculpture of the outer structure of the Nosema cell wall (Fig. 1C) $)^{39,40}$.

In addition, molecular biology methods were applied to confirm our findings. The microsporidia immobilised on the tapes exposed to the apiary and the BG air were analysed by a PCR amplification of the 16S rRNA gene in order to determine the Nosema species (Fig. 2A,B). We detected amplicons corresponding to the expected size of the PCR products for N. apis (for $269 \mathrm{bp}$ ) and N. ceranae (218-219bp) only in the apiary (Fig. 2A). By contrast, the amplification of the biological material trapped on the tapes exposed to the laboratory air resulted in no PCR products corresponding to the DNA of N. apis or N. ceranae spores. Identical results were obtained when the control tapes was exposed to the air in the BG, which was not influenced by the presence of honeybee colonies (Fig. 2B). The specificity of the PCR products was verified by Sanger sequencing, either directly (in the case of Nosema ceranae) or by employing a sub-cloning step (Nosema apis). The amplicons derived from Nosema ceranae were homogenous and were found to be an exact match to the rRNA gene sequences deposited in the public databases (NCBI) that were derived from several different strains of N. ceranae (NCBI accession number JQ639315.1). In the case of Nosema apis, by employing the sub-cloning step, we were able to reveal a relatively high level of diversity among the analysed amplicons: while all of the obtained sequences matched with regard to the N. apis rRNA gene, the level of identity ranged from $95.4 \%$ to $97 \%$ due to the occurrence of substitutions and 1-bp indels, which were most likely naturally occurring polymorphisms (NCBI accession number U97150). It is highly unlikely that the diversity among the analysed amplicons was a product of amplification errors, because identical reagents and procedures were used to amplify both the N. apis and N. ceranae DNA, and no such diversity was observed in the case of N. ceranae. The Real-Time PCR also confirmed the presence of N. apis and N. ceranae cells in each of the tested tapes from the apiary. The average copy number of $N$. apis was estimated at $14.4 \times 10^{4}$ copies per $1 \mathrm{~cm}^{2}$ of the tape; whereas the number of $N$. ceranae was $2.24 \times 10^{4}$ copies per tape per $1 \mathrm{~cm}^{2}$ $\left(\mathrm{t}_{(16)}=-2.518 ; \mathrm{p}=0.031\right)$ (Table 2).

Nosema microsporidia are obligate intracellular pathogens $\mathrm{s}^{41,42}$ that infect honeybees and bumblebees ${ }^{32}$. Since biological objects measuring from 1 to $5 \mu \mathrm{m}$ in diameter are classified as bioaerosols ${ }^{43}$, the $2-6 \mu \mathrm{m}$ Nosema microsporidia ${ }^{6,8}$ can be classified as wind-dispersed bioaerosols. Bioaerosols are carried in the air and can be deposited on various surfaces in the natural environment, including on flowers ${ }^{37,43}$. The deposition of bioaerosols in the natural environment is influenced by both environmental (e.g. air currents, relative humidity and temperature) and physical factors (including the particle size, density and shape) $)^{44,45}$.

In our opinion, environmental factors can also influence the rate of deposition of Nosema spores (as bioareosols) and the time of their persistence on the surface, which may even contribute to a periodic increase in the concentration of spores in the air. This can be confirmed in the present study by the fluctuations in the number of spores immobilised on the tapes that occurred from the beginning of June to the end of August (Table 1). Nosema spp. can be spread on a large scale by Merops apiaster and Loxostege sticticalis due to a high migratory activity ${ }^{27-29}$.

We identified Nosema spores in the air of an open apiary field (containing 30 colonies), but we did not identify them in the BG, where there were no bee colonies within a radius of $4 \mathrm{~km}$ (Fig. $2 \mathrm{~B}$ ). This was probably due to the lower number of bees present in the air of the BG (Fig. 2B). The greatest number of spores per $1 \mathrm{~m}^{3}$ of air in the apiary was noted in August (Table 1). These results were confirmed by the Real-Time PCR analysis, which demonstrated a higher average number of DNA Nosema spp. copies in August $\left(5.12 \times 10^{4}\right)$ than in July $\left(2.01 \times 10^{4}\right)\left(\mathrm{F}_{(15)}=16.438 ; \mathrm{p}=0.021\right)$ (Table 2). Simultaneously, we observed a larger number of infected foragers in the bee colonies in August/September. August is the driest month in our latitude; therefore we believe that such conditions promoted the transfer of spores from fast-drying faeces by the wind and facilitated their spread in the air. During the spore collection that took place at the beginning of the experiment, the uninfected colony prevalence was $84 \%$; whereas this value was $76 \%$ at the end of the experiment. The mean number of Nosema spp. per forager in the infected colonies increased from $7.4 \times 10^{6}$ in June to $28.6 \times 10^{6}$ in August $\left(\mathrm{F}_{(29)}=22.96\right.$; $\mathrm{p}=0.000014)$. The higher number of infected foragers in the apiary probably increased the concentration of spores in the air in August, compared with the level that was noted in early June; hence, we observed an increased number of spores trapped from the air (Table 1). Nosema spp. spores are transferred to the apiary air indirectly via the faecal-oral route ${ }^{10,11,13,37}$, thereby further increasing the risk of infection for individual bees and colonies (in an apiary consisting of 30 colonies).

Bigliardi and Sacchi ${ }^{41}$ suggested that spores present outside the host cells are metabolically inactive. Nosema spp. microsporidia generate environmental spores, which exhibit thermotolerance and a resistance to desiccation, 

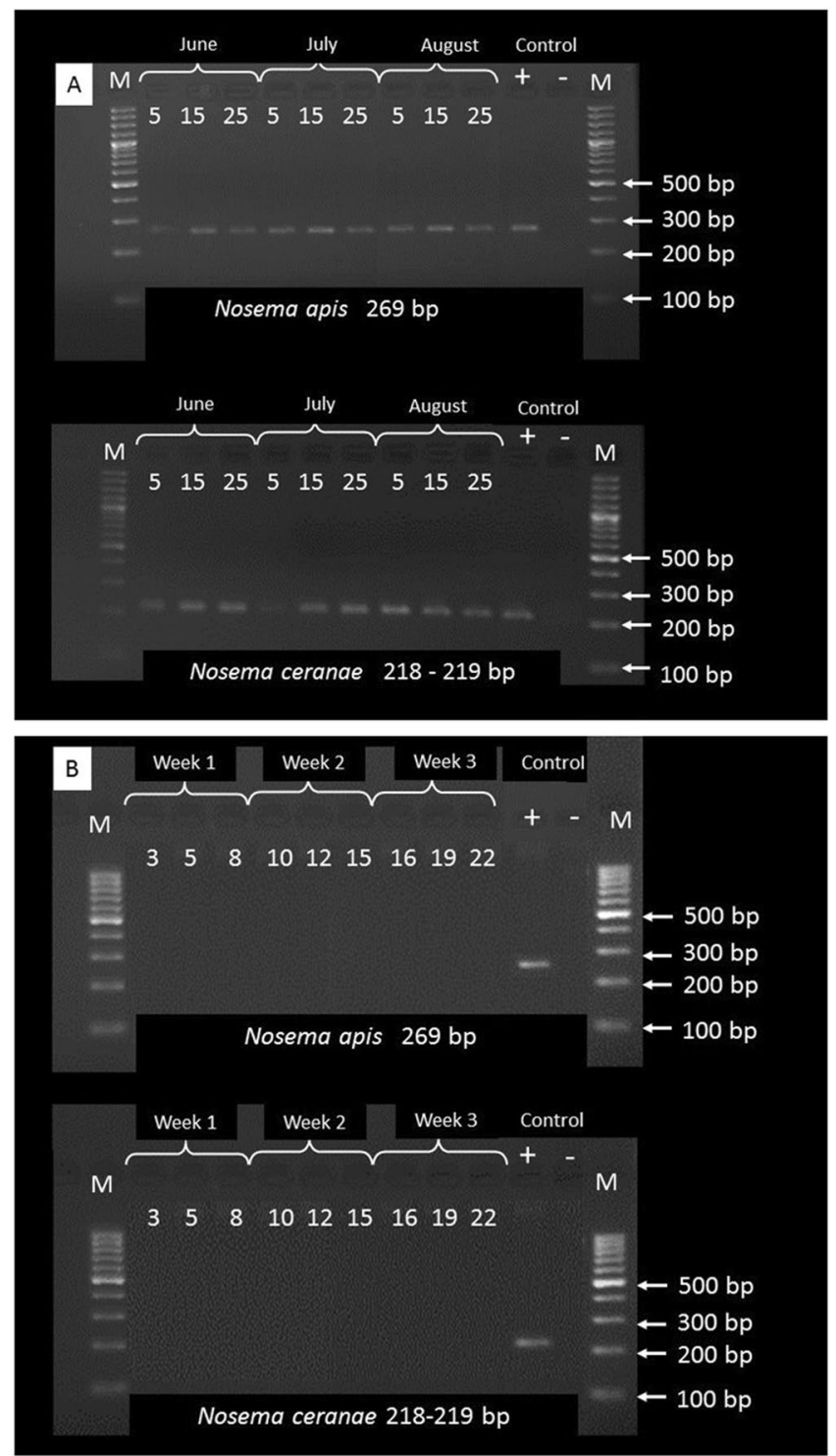

Figure 2. Experimental procedures. (A) $2 \%$ agarose gels showing PCR products amplified from Nosema ceranae and Nosema apis DNA extracted from the spores captured on apiary tapes. M: Molecular weight marker (Gene ruler, 1-kb ladder, Thermo Scientific). Lanes 5-25 correspond to the experimental days represented by the tape fragments selected for the PCR analysis. (B) $2 \%$ agarose gels showing absence of PCR products amplified from Nosema ceranae and Nosema apis DNA extracted from the spores captured on tapes from the air in the Botanical Garden. M: Molecular weight marker (Gene ruler, 1-kb ladder, Thermo Scientific). Lanes 3-22 correspond to the experimental days represented by the tape fragments selected for the PCR analysis.

and this plays an important role for epidemiology and for the laboratory studies of honeybee microsporidio$\operatorname{sis}^{46,47}$. However, at present there are no reports available on the capability of Nosema spores coming from the air to become infective after entering the bee's digestive tract. An assessment of the infectivity of Nosema spores present in the air (i.e. those trapped on the tape) may not be feasible, as the tapes were coated with silicone oil, which can affect the viability of the spores.

Although we detected less than 5 Nosema spores in $1 \mathrm{~m}^{3}$ of air in the apiary containing 30 colonies (Table 1), an increase of this number to 72 spores per day ( 5 spores $\times 14.4 \mathrm{~m}^{3}$ of aerobiological sampler capacity) may increase the risk of infection for a single bee or a bee colony. It is difficult to compare this number with any other data, as there are no reports on the minimal number of spores responsible for causing infection in natural conditions. Bailey ${ }^{48,49}$ has found that one worker bee can be infected by a median infective dose below 100 spores of Nosema apis. In addition, Lotmar ${ }^{50}$ needed 1000 spores per bee to produce N. apis infections in $28 \%$ of the tested insects. However, McGowan et al. ${ }^{51}$ needed fewer spores to infect one bee. The median infective dose (ID50) was determined to be $149 \mathrm{~N}$. ceranae spores per bee, and the minimum dose capable of causing a detectable infection was 1.28 spores.

Another example is the microsporidian Vairimorpha necatrix (Microsporida: Nosematidae) that infects Trichoplusia ni (Lepidoptera: Noctuidae), where infective doses as low as 11 spores have been shown to kill over 


\begin{tabular}{|c|c|c|c|c|}
\hline \multicolumn{2}{|c|}{ Tapes from the Apiary } & \multicolumn{3}{|c|}{ Copy number $\times 10^{4}$} \\
\hline Month & Days & N. ceranae & N. apis & Mean \\
\hline \multirow{3}{*}{ June } & 5 & 2.60 & 44.4 & \multirow{3}{*}{$17.9^{\mathrm{b}}$} \\
\hline & 15 & 2.51 & 52.1 & \\
\hline & 25 & 2.27 & 3.38 & \\
\hline \multirow{3}{*}{ July } & 5 & 2.29 & 0.94 & \multirow{3}{*}{$2.01^{\mathrm{a}}$} \\
\hline & 15 & 0.97 & 3.35 & \\
\hline & 25 & 1.37 & 4.11 & \\
\hline \multirow{3}{*}{ August } & 5 & 1.90 & 9.08 & \multirow{3}{*}{$5.12^{\mathrm{b}}$} \\
\hline & 15 & 4.40 & 7.31 & \\
\hline & 25 & 2.82 & 5.22 & \\
\hline \multicolumn{2}{|l|}{ Mean } & $2.24^{*}$ & $14.4^{*}$ & \\
\hline \multicolumn{2}{|c|}{ Positive control } & 51700 & 33000 & \\
\hline
\end{tabular}

Table 2. Quantitative analysis of the N. apis and N. ceranea genetic material in the tested tapes. The copy number was expressed as the average DNA copy number per $1 \mathrm{~cm}^{2}$ of the tape. *asterisks denote significant differences in the copy number per $1 \mathrm{~cm}^{2}$ of the tape between $N$. ceranae and $N$. apis (t-Student test, $\left.\mathrm{t}_{(16)}=-2.518, \mathrm{p}=0.031\right)$. $\mathrm{a}, \mathrm{b}$ - the different small letters denote statistically significant differences between the copy number of Nosema spores per $1 \mathrm{~cm}^{2}$ of the tape in the month (one-way ANOVA, $\mathrm{F}_{(15)}=16.438, \mathrm{p}=0.021$; Tukey test, $\mathrm{p} \leq 0.05)$.

$50 \%$ of the host larva ${ }^{52}$. The infective dose of microsporidia depends on the species and its virulence, as well as on the age and physiological stage of a single host or the entire colony. Given the higher virulence of Nosema ceranae compared to N. apis ${ }^{53,54}$, and since the infection process may last for longer than 1 day $^{9}, 5$ spores in $1 \mathrm{~m}^{3}$ seems to be a sufficient number to cause the infection of individual bees and the entire bee colony. Furthermore, it should be noted that the capacity of the sampler allowed for the analysis of only $14.4 \mathrm{~m}^{3}$ of air per day; however, more air passes through the apiary during the day, which may significantly increase the number of spores transferred to the bee colonies.

Microsporidia spores are commonly found in surface water (one of the sources of infection) ${ }^{55}$, but insects can also ingest the parasite during foraging, food processing or grooming ${ }^{13-15}$. Graystock et al. ${ }^{37}$ suggested that spores can be spread between the bee and the flower through the spore's adhesion to the bee cuticle and subsequent rubbing them off onto the flower surfaces. Some parasite dispersal may be also associated with the formation of bee pollen and bee bread ${ }^{12}$. When the pollen is too dry, foragers add drops of nectar from the crop to glue the grains together and to form bee pollen ${ }^{13-15,56}$. The spores are then regurgitated along with the drop of nectar from the crop that may contain Nosema spores acquired from contaminated food. Since healthy and Nosema-infected honeybees visit the same flowering plants during their nectar and pollen collection, the spore transmission between the bee and the flower increases the risk of spreading Nosema to the colony. Such a phenomenon has been confirmed in the case of bumblebees. When bumblebees foraged on flowers that had been visited by honeybees, $23 \%$ of these insects, which were collected from the entrances of their hives, exhibited the presence of N. ceranae $e^{37}$.

The spores present on the honeybee's body and on flowers are subject to drying under the influence of environmental factors (sun and wind). Thus, the small size $(2-6 \mu \mathrm{m})$ of Nosema spp. spores ${ }^{6,8}$ enables them to be transferred as bioaerosols by wind in the air. To evaluate this possibility, the Nosema spp. spores were collected in the present study from the air in the apiary, where they were possibly dropped from the surfaces of the bodies of the foragers returning to the colonies together with the bee pollen ${ }^{12}$.

The foragers exhibited the highest rate of Nosema infection in August, i.e. in the period when we observed the greatest number of airborne Nosema spores. This indicates that the infected bees could generate the bioaerosol either during flights and defecation, or by transporting Nosema spores on their bodies, which were then blown away by the wind and deposited on the tapes of the Hirst-type trap (Table 1). All of the aforementioned routes of horizontal transmission of Nosema are highly possible ways of spreading the spores in any apiary ${ }^{37,57-59}$. Honeybees leave excrement near the apiary; then, when it is dry, the spores can be transported by the wind onto the anthers of blooming flowers and collected again along with the pollen ${ }^{12}$. We detected a higher number of copies of N. apis in comparison to N. ceranae in the tested tapes. This was consistent with results obtained by Copley et al..$^{60}$, which suggest that $N$. apis is more abundant in samples of bottom scraps from infected colonies when compared to N. ceranae.

Honeybees are often housed in commercial apiaries containing tens to thousands of colonies. Thus, the high density of bees ${ }^{61}$ increases the horizontal transmission of diseases. The rate of parasite transmission between bees will predictably increase when the density of the pollinators in the air increases ${ }^{62}$. In addition, the increased competition for resources caused by the introduction of a high density of managed honeybees or commercially-produced bumblebees may also create stress for wild bees. Increased competition in foraging may have negative effects on some immune system components, impairing the resistance to parasites ${ }^{63-68}$. N. ceranae is an emergent honeybee parasite that is abundant at some sites but completely absent at others. Accordingly, $N$. ceranae has been implicated in the collapse of honeybee colonies in some, but not all, areas ${ }^{7,10,17,54,69,70}$.

As numerous studies on Nosema-infected honeybees are carried out in a laboratory using cage tests, we decided to check whether Nosema microsporidia will spread in the laboratory air. In the present study, we did not find Nosema spores in the laboratory air, presumably because the ventilation around the cages with bees 


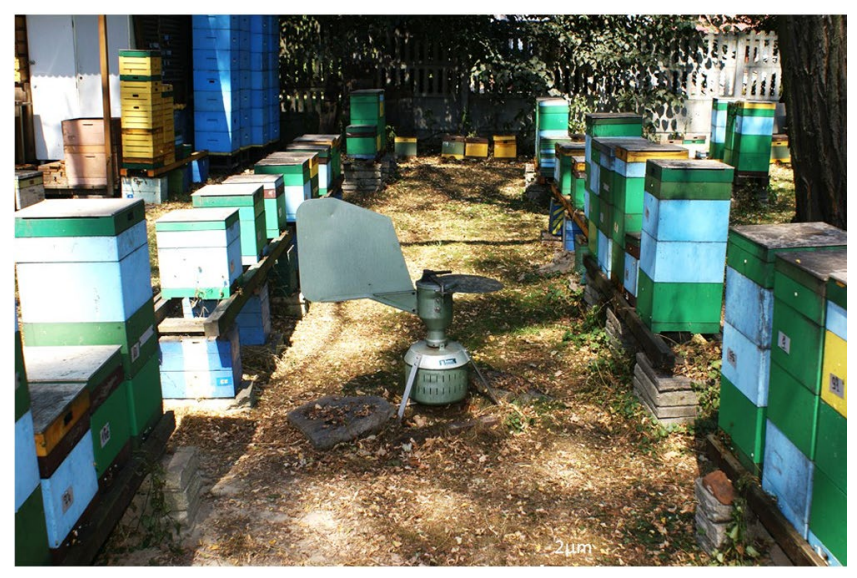

Figure 3. Experimental procedures. A Hirst-type spore trap was placed among the hives.

was insufficient to lift the spores into the laboratory air. The low number of honeybees in the laboratory and the restricted space for flying in the cages limited the spread of the spores into the laboratory air; also, because the bees maintained in the cages could not fly, they did not collect pollen or excrete faeces. However, during the laboratory experiment, there were open ventilation holes in the bees' cages, through which the Nosema microsporidia may have been transported into the laboratory air. Nonetheless, we did not detect the presence of Nosema microsporidia in the laboratory air. These results provide confirmation that experiments with both infected and non-infected honeybees can be performed in one laboratory.

\section{Conclusions}

Our research adds knowledge about the transfer of Nosema microsporidia in the natural environment. Using the volumetric method with a Hirst-type sampler, we have shown a new route for the spreading of spores via the air in the investigated apiary. The results obtained in our apiary in one beekeeping season indicated the months associated with the greatest risk of a bee colony infection with Nosema. However, further investigations in other environments worldwide are required in order to evaluate the risk of the infection with Nosema in particular seasons. If our observations are confirmed in future studies, the proposed method will complement other methods of monitoring the levels of Nosema infection in apiaries. In our opinion, it could also have a potential application and provide useful information on air monitoring in areas characterised by a high density of crop plants before pollination. This is especially important in the case of wandering apiaries, which should be placed in Nosema-free areas.

\section{Materials and Methods}

Field experiment design. From 1 June to 1 September 2015, spores were collected from the apiary of the University of Life Sciences in Lublin $\left(51^{\circ} 13^{\prime} \mathrm{N}, 22^{\circ} 38^{\prime} \mathrm{E}\right)$. Between 1 June and 1 September 2016, spores were also collected from the Botanical Garden (BG) of the University of Maria Curie-Skłodowska $\left(51^{\circ} 26^{\prime} \mathrm{N}, 22^{\circ} 51^{\prime} \mathrm{E}\right)$ without the presence of bee colonies within a radius of $4 \mathrm{~km}$, which was a control relative to the spores collected from the apiary. The spores present in the air were monitored by the volumetric method using a Hirst-type sampler (Burkard Manufacturing Company Ltd.) placed between the rows of hives (Fig. 3). On 1 June, immediately after installing the Hirst-type sampler, the mean rate of Nosema spp. infections in foragers and the prevalence of infections in the apiary were estimated with the microscopic method ${ }^{71}$. Briefly, 30 bees from each of the 30 colonies were homogenised in $30 \mathrm{~mL}$ of distilled water. The homogenous suspension was then placed in a Bürker haemocytometer. The spores in each square were counted under a light microscope at $400 \times$ magnification and were expressed as the number of spores per honeybee. On 1 September, after the spore trapping from the air had ceased, the foragers in the bee colonies were again examined to detect the presence of Nosema spores.

Laboratory experiment design. Cage tests were carried out with infected bees and spores, which were trapped in the laboratory air for examination in the laboratories at the University of Life Sciences and at the University of Maria Curie-Skłodowska in Lublin. Brood combs were taken on the 20th day of development, which were placed in an environmental chamber, and maintained at a constant temperature $\left(34^{\circ} \mathrm{C}\right)$ and relative humidity $(60 \%)$ to obtain 1 -day-old honeybees. The cage tests were performed in 60 wooden cages $(12 \times 12 \times 4 \mathrm{~cm})$ equipped with glass screens on the front and having ventilation holes. There were no combs or wax foundations in the cages. The experimental groups comprised 1-day-old bees that were maintained in laboratory conditions $\left(25^{\circ} \mathrm{C} ; \mathrm{H}=65 \%\right)$. On the $3 \mathrm{rd}$ day after emerging, the honeybees were inoculated by mass provisioning with a solution of $N$. ceranae and $N$. apis spores $\left(5 \times 10^{6} \text { spores } / \mathrm{mL}\right)^{72}$, which were previously purified by single centrifugation (20,000 g; $30 \mathrm{~min})$ in the Percoll gradient ${ }^{73}$. The pellets of Nosema spp. obtained were re-suspended in sugar syrup (1:1). Subsequently, the honeybees in the cages were provisioned with the spore suspension over three days, and were then maintained in the laboratory room for another 19 days. The average quantity of spores $\left(5.25 \times 10^{5}\right)$ administered to each bee was estimated from the total volume $(4.2 \mathrm{~mL})$ of the spore-containing syrup consumed by all the bees in a cage. 
Spores were collected between 1 June and 22 June 2017 (Burkard Manufacturing Company Ltd.), with a Hirst-type sampler which was placed at the height of the ventilation holes in the bee cages. We applied the volumetric method to monitor the spores as described for the apiary and BG tests.

Nosema spp. trapping method. Before the experiments for monitoring Nosema spores in the air with the Hirst-type spore trap (which is used in aerobiological studies), a blind probe was conducted. The aim was to determine whether faecal particles were deposited on the sampler tapes collecting the spores present in the air. The probe operated by placing the faeces near the air inlets of the sampler located in the BG, where there were no bee colonies within a radius of $4 \mathrm{~km}$. The macro- and microscopic analysis, which was performed after 7 days of exposure, confirmed the absence of faecal lumps on the tape.

This allowed us to conduct an experiment in which the spores were monitored using the volumetric method. The Hirst-type spore trap (Burkard Manufacturing Company Ltd.) was placed at ground level in the apiary and the BG and on the floor in the laboratory ${ }^{74}$. The trap operated continuously with a negative pressure at $0.01 \mathrm{~m}^{3}$ $(10 \mathrm{~L}) \mathrm{min}^{-1}\left(14.4 \mathrm{~m}^{3}\right.$ of air per day) through a critical orifice $(14 \times 2 \mathrm{~mm})$ facing the air flow with the use of a wind vane. The air flow was provided by an external vacuum pump. A rotating drum, to which particles adhere inside each trap, was driven by a clockwork mechanism that moved at a constant speed of $2 \mathrm{~mm} \mathrm{~h}^{-1}(48 \mathrm{~mm}$ per day) and completing one full rotation per week. The drum was covered with approximately $345 \mathrm{~mm}$ of Melinex tape ( $48 \mathrm{~mm}$ per day $\times 7+9 \mathrm{~mm}$ for mounting the tape) coated with silicone oil, which has been suggested for use in varying weather conditions ${ }^{75}$. Particles in the air flow were impacted on the tape due to the inertia of momentum ${ }^{76}$. The tape was changed once a week at the same hour of the day (9 AM) and was divided on a cutting block into seven equal segments corresponding to each sampling day ${ }^{77}$. Each tape segment with trapped spores was cut lengthwise into two fragments. One segment was used to make glycerine jelly preparations ${ }^{74}$, which were analysed afterwards using a Nikon light microscope ( $\times 400$ along two horizontal lines, $48 \mathrm{~mm}$ long) (Fig. 1A), a Nomarski interference contrast microscope (Fig. 1B) and a scanning electron microscope (Fig. 1C). The other fragment of the tape was stored at $-20^{\circ} \mathrm{C}$ until the DNA extraction was performed. Nine tape fragments were randomly selected from the apiary and BG tapes (three fragments from the tapes representing Days 5, 15 and 25 were selected for each month of the spore collection). We also selected nine tape fragments randomly from the cage tests (these tape fragments represented Days 3, 5 and 8 in Week 1; Days 10, 12 and 15 in Week 2; and Days 16, 19 and 22 in Week 3). The number of Nosema spores from all tapes was multiplied by a correction factor to estimate the number of spores on the entire microscope slide. The results were expressed as the average daily concentration of spores in $1 \mathrm{~m}^{3}$ of air.

DNA extraction from spore samples, PCR, Real-Time PCR and sequencing conditions. Lysis buffer $(180 \mu \mathrm{L})$ and proteinase $\mathrm{K}(20 \mu \mathrm{L})$ were added to each tape fragment for $24 \mathrm{~h}$, and the total DNA was isolated using the DNeasy Blood and Tissue Kit (Qiagen) in accordance with the manufacturer's instructions. To identify the Nosema species, the total DNA was analysed by PCR using the 218 MITOC (FOR 5-CGGCGACGATGTGATATGAAAATATTAA) and 321APIS (FOR 5-GGGGGCATGTCTTTGAC GTACTATGTA) primers as described by Martin-Hernandez et al. ${ }^{78}$. The PCR was performed using the Taq PCR Core Kit (Qiagen). In a total volume of $30 \mu \mathrm{L}$, the reaction mixture included $6 \mu \mathrm{L}$ of the DNA sample, $1 \times$ PCR buffer, $1 \times \mathrm{Q}$ solution, $4 \mathrm{mM}$ of $\mathrm{MgCl}_{2}, 0.2 \mathrm{mM}$ of each dNTP, $0.4 \mu \mathrm{M}$ of each primer and $2 \mathrm{U}$ of Taq DNA polymerase. The PCR conditions were as follows: $10 \mathrm{~min}$ at $95^{\circ} \mathrm{C}$, followed by $35 \mathrm{cycles}$ of $30 \mathrm{~s}$ at $95^{\circ} \mathrm{C}, 30 \mathrm{~s}$ at $55.8^{\circ} \mathrm{C}$, and $45 \mathrm{~s}$ at $72^{\circ} \mathrm{C}$, with a final extension at $72^{\circ} \mathrm{C}$ for $7 \mathrm{~min}$. The PCR products were electrophoresed on a $2 \%$ agarose gel and analysed under a UV light.

To additionally confirm the presence of the Nosema species representatives in the tested tapes, a Real-Time PCR analysis was carried out. Two pairs of primers were used in the reaction - NosAF5-CATGTCTTTGACGTACTATGTACT and NosAR-ACTAGCTGATAGGTCTCACTCT for the detection of Nosema apis (product length $132 \mathrm{bp}$ ), as well as NosCF-5-ACGTAATACGATCAGATGGTCAGC and NosCR5-CTCGAACGAAATGTCCCATCA for the detection of Nosema ceranae (product length $168 \mathrm{bp}$ ). To avoid non-specific amplification, the primer NosCF contains two mismatched nucleotides at the $3^{\prime}$ end, which prevent hybridisation with the $N$. apis template. NosAF was designed for a region that contains five mismatched nucleotides, which prevent hybridisation with the $N$. ceranae template at the $3^{\prime}$ end. Both of the primer pairs were first tested in a conventional PCR to confirm the amplification of only the specific target. Specificity was confirmed by sequencing the amplification products.

The Real-Time PCR was prepared using $1 \times$ PowerUp $^{\mathrm{TM}}$ SYBR $^{\circledR}$ Green Master Mix (Thermo Fisher Scientific), $0.2 \mu \mathrm{m}$ of NosAF and NosAR primers (master mix for the detection of N. apis), and $0.15 \mu \mathrm{m}$ NosC and NosCR primers (master mix for the detection of $N$. cerenae) in a total volume of $20 \mu$ in the 7500 Fast Real-Time PCR System. The cycling conditions were as follows: $2 \mathrm{~min}$ at $50^{\circ} \mathrm{C}$ (UDG activation) and $2 \mathrm{~min}$ at $95^{\circ} \mathrm{C}$, followed by 40 cycles of $3 \mathrm{~s}$ at $95^{\circ} \mathrm{C}$ and $30 \mathrm{~s}$ at $60^{\circ} \mathrm{C}$. A quantitative determination was performed in order to evaluate the average number of copies of $N$. apis and $N$. ceranae in the tested samples. Serial dilutions of $1 \times 10^{7}$ copies $/ \mu \mathrm{l}$, $1 \times 10^{6} \mathrm{copies} / \mu \mathrm{l}, 1 \times 10^{5}$ copies $/ \mu \mathrm{l}, 1 \times 10^{4} \mathrm{copies} / \mu \mathrm{l}, 1 \times 10^{3} \mathrm{copies} / \mu \mathrm{l}, 1 \times 10^{2} \mathrm{copies} / \mu \mathrm{l}$ and $1 \times 10^{1} \mathrm{copies} / \mu \mathrm{l}$ were used to prepare the standard curve. These dilutions were prepared using purified PCR products with known concentrations. Positive and no template controls were run with each plate. The products of the amplifications were separated on $2 \%$ agarose gel to exclude the presence of primer-dimer structures and non-specific products. The copy number was expressed as the average copy number per $1 \mathrm{~cm}^{2}$ of the tape.

The specificity of the PCR products was verified by the Sanger sequencing of the amplicons excised from the agarose gel. The Nosema ceranae rRNA gene amplicons were sequenced directly, whereas the Nosema apis amplicons were cloned prior to sequencing. The PCR products were cloned in the pGEM-T Easy vector (Promega) and transformed into E. coli cells, which were subjected to blue/white screening. Several individual plasmids isolated from the white colonies were then sequenced using T7 (5'-TAATACGACTCACTATAGG) or 
SP6 (5'-ATTTAGGTGACACTATAG) primers. The analysis was performed in triplicate. The obtained sequences were checked against the public nucleotide databases (NCBI) and were then submitted under accession numbers MG770412 to MG770420.

Scanning electron microscopy. To confirm that the spores observed on the tape under the light and Normarsky microscopes were Nosema spp. spores, the same sections of the tapes with the trapped spores were prepared for a scanning electron microscopy (SEM). Briefly, the tapes were fixed for $24 \mathrm{~h}$ in $5 \%$ glutaraldehyde $(\mathrm{v} / \mathrm{v})$ in a $0.1 \mathrm{M}$ phosphate buffer $(\mathrm{pH} 7.3)$. After fixation, the samples were washed in saline and dehydrated in an alcohol series, then dried in a critical point dryer (CPD7501, Polaron Range) and sputter-coated (SC 7620, Polaron Range) with an Au/Pd layer. The samples were examined in a LEO 1430 VP SEM, as well as being measured and photographed.

Statistical analysis. The statistical analysis was performed using SAS software Version 9.5 (Statistical Analysis System Institute, Cary, NC). The numbers of Nosema spp. per forager in the infected colonies from June to August were compared using a one-way ANOVA, Tukey test. Differences of $p \leq 0.05$ were considered significant. The DNA copy numbers per $1 \mathrm{~cm}^{2}$ of the tape were compared for $N$. ceranae and N. apis using the t-Student test. The number of spores and the DNA copy number of Nosema spp. identified on the tapes from June to August were compared using the one-way ANOVA, followed by Tukey test. Differences of $\mathrm{p} \leq 0.05$ were considered significant.

\section{References}

1. Weiss, L. M. \& Becnel, J. J. Microsporidia: Pathogens of Opportunity. Wiley-Blackwell; Oxford First Edition. Wiley Blackwell. https:// doi.org/10.1002/9781118395264 (2014).

2. Han, B. \& Weiss, L. M. Microsporidia: Obligate Intracellular Pathogens within the Fungal Kingdom. Microbiol Spectr 5, https://doi. org/10.1128/microbiolspec.FUNK-0018-2016 (2017).

3. Adl, S. et al. The new higher level classification of eukaryotes with emphasis on the taxonomy of protists. J. Eukaryot. Microbiol. 52, 399-451 (2005).

4. Huang, W. F., Solter, L. F., Yau, P. M. \& Imai, B. S. Nosema ceranae escapes fumagillin control in honey bees. Plos Pathog, https://doi. org/10.1371/journal.ppat.1003185 (2013).

5. Zander, E. Tierische Parasiten als Krankenheitserreger bei der Biene. Münch. Bienenztg. 31, 196-204 (1909).

6. Fries, I., Feng, F., da Silva, A., Slemenda, S. B. \& Pieniazek, N. J. Nosema ceranae n.sp. (Microspora, Nosematidae), morphological and molecular characterization of a microsporidian parasite of the Asian honey bee Apis cerana (Hymenoptera, Apidae). Eur. J. Protistol. 32, 356-365 (1996).

7. Klee, J. et al. Widespread dispersal of the microsporidian Nosema ceranae, an emergent pathogen of the western honey bee, Apis mellifera. J. Invertebr. Pathol. 96, 1-10 (2007).

8. Higes, M., Martín-Hernández, R. \& Meana, A. Nosema ceranae in Europe: an emergent type C nosemosis. Apidologie. https://doi. org/10.1051/apido/2010019 (2010).

9. Higes, M., García-Palencia, P., Martín-Hernández, R. \& Meana, A. Experimental infection of Apis mellifera honeybees with Nosema ceranae (Microsporidia). J. Invertebr. Pathol, https://doi.org/10.1016/j.jip.2006.11.001(2007).

10. Fries, I. Nosema ceranae in European honey bees (Apis mellifera). J. Invertebr. Pathol. 103, 73-79 (2010).

11. Bailey, L. The infection of the ventriculus of the adult honeybee by Nosema apis (Zander). Parasitology. 45, 86-94 (1955).

12. Sokół, R. \& Michalczyk, M. Detection of Nosema spp. in worker bees, pollen and bee bread during the honey flow season. Acta. Vet. Brno, https://doi.org/10.2754/avb201685030261 (2016).

13. Webster, T. C. Nosema apis spore transmission among honey bees. Am. Bee. J. 133, 869-870 (1993).

14. Bulla, L. A. Jr. In: Comparative Pathobiology. Vol. 1: Biology of Microsporidia (1976); Vol. 2: Systematics of the Microsporidia, Lee A. \& Cheng T.C., eds (Plenum Press, New York, USA, and London, UK, 1977).

15. Fries, I. Nosema apis - A parasite in the honey bee colony. Bee World 74, 5-19 (1993).

16. L'Arrivée, J. C. M. The effect of sampling sites on Nosema determination. J. Insect. Pathol. 5, 349-355 (1963).

17. Higes, M. et al. How natural infection by Nosema ceranae causes honeybee colony collapse. Environ. Microbiol. 10, 2659-2669 (2008).

18. Meana, A., Martín-Hernández, R. \& Higes, M. The reliability of spore counts to diagnose Nosema ceranae infections in honey bees. J. Apic. Res, https://doi.org/10.3896/IBRA.1.49.2.12 (2010).

19. Botías, C. et al. Further evidence of an oriental origin for Nosema ceranae (Microsporidia: Nosematidae). J. Invertebr. Pathol. 110, 108-113 (2012)

20. Martín-Hernández, R. et al. Microsporidia infecting Apis mellifera: coexistence or competition. Is Nosema ceranae replacing Nosema apis? Environ. Microbiol, https://doi.org/10.1111/j.1462-2920.2011.02645.x (2012).

21. Smart, M. D. \& Sheppard, W. S. Nosema ceranae in age cohorts of the western honey bee (Apis mellifera). J. Invertebr. Pathol. 109, 148-151 (2012).

22. Beshers, S. N., Huang, Z. H., Oono, Y. \& Robinson, G. E. Social inhibition and regulation of temporal polyethism in honey bees. J. Theor. Biol. 213, 416-479 (2001).

23. Webster, T. C., Pomper, K. W., Hunt, G., Thacker, E. M. \& Jones, S. C. Nosema apis infection in worker and queen Apis mellifera. Apidologie, https://doi.org/10.1051/apido:2003063 (2004).

24. Chen, Y., Evans, J. D., Smith, I. B. \& Pettis, J. S. Nosema ceranae is a long-present and wide-spread microsporidian infection of the European honey bee (Apis mellifera) in the United States. J. Invertebr. Pathol, https://doi.org/10.1016/j.jip.2007.07.010 (2008).

25. van Steen, J. J. M. \& Blom, M. P. K. Pathogen transmission in insect pollinators. (Plant Research International, onderdeel van Wageningen UR Business Unit Biointeracties en Plantgezondheid, 2010).

26. Ozgor, E., Celebier, I., Ulusoy, M. \& Keskin, N. First detection of Nosema ceranae and Nosema apis in greater wax moth Galleria mellonella. J. Apic. Sci, https://doi.org/10.1515/jas-2017-0015 (2017).

27. Higes, M. et al. Regurgitated pellets of Merops apiaster as fomites of infective Nosema ceranae (Microsporidia) spores. Environ. Microbiol, https://doi.org/10.1111/j.1462-2920.2007.01548.x (2008).

28. Valera, F., Martín-Hernández, R. \& Higes M. Evaluation of large-scale dissemination of Nosema ceranae spores by European beeeaters Merops apiaster. Environ. Microbiol Rep, https://doi.org/10.1111/j.1758-2229.2010.00186.x (2011).

29. Malysh, J.M., Ignatieva, A. N, Artokhin, K. S., Frolov, A. N., Tokarev, Y. S. Natural infection of the beet webworm Loxostege sticticalis L. (Lepidoptera: Crambidae) with three Microsporidia and host switching in Nosema ceranae. Parasitol. Res, https://doi.org/10.1007/ s00436-018-5987-3 (2018).

30. Colla, S. R., Otterstatter, M. C., Gegear, R. J. \& Thomson, J. D. Plight of the bumble bee: pathogen spillover from commercial to wild populations. Biol. Conserv. 129, 461-467 (2006). 
31. Genersch, E., Yue, C., Fries, I. \& de Miranda, J. R. Detection of deformed wing virus, a honey bee viral pathogen, in bumble bees (Bombus terrestris and Bombus pascuorum) with wing deformities. J. Invertebr. Pathol. 91, 61-63 (2006).

32. Plischuk, S. et al. South American native bumblebees (Hymenoptera: Apidae) infected by Nosema ceranae (Microsporidia), an emerging pathogen of honeybees (Apis mellifera). Environ. Microbiol. Rep, https://doi.org/10.1111/j.1758-2229.2009.00018.x (2009).

33. Evison, S. E. F. et al. Pervasiveness of parasites in pollinators. Plos One, https://doi.org/10.1371/journal.pone.0030641 (2012).

34. Graystock, P., Yates, K., Darvill, B., Goulson, D. \& Hughes, W. O. H. Emerging dangers: deadly effects of an emergent parasite in a new pollinator host. J. Invertebr. Pathol. 114, 114-119 (2013).

35. Furst, M. A., McMahon, D. P., Osborne, J. L., Paxton, R. J. \& Brown, M. J. F. Disease associations between honeybees and bumblebees as a threat to wild pollinators. Nature 506, 364-366 (2014).

36. Durrer, S. \& Schmid-Hempel, P. Shared use of flowers leads to horizontal pathogen transmission. Proc. R. Soc. Lond. B. 258, 299-302 (1994).

37. Graystock, P., Goulson, D. \& Hughes, W. O. H. Parasites in bloom: flowers aid dispersal and transmission of pollinator parasites within and between bee species. Proc. R. Soc. B. https://doi.org/10.1098/rspb.2015.1371 (2015).

38. Rüegg, P. New stowaway discovered in the bumblebee’s gut. Science. http://www.ethlife.ethz.ch/archive_articles/100719_neuer_ parasit_per/index_EN.html (2010).

39. Ptaszyńska, A., Borsuk, G., Mułenko, W., Demetraki-Paleolog, J. Differentiation of Nosema apis and Nosema ceranae spores under Scanning Electron Microscopy (SEM). J. Apic. Res, https://doi.org/10.3896/ibra.1.53.5.02 (2014).

40. Ptaszyńska, A. et al. Porphyrins inactivate Nosema spp. microsporidia. Sci. Rep, https://doi.org/10.1038/s41598-018-23678-8 (2018).

41. Bigliardi, E. \& Sacchi, L. Cell biology and invasion of the microsporidia. Microbes. Infect. 3, 373-379 (2001).

42. Franzen, C. Microsporidia: how can they invade other cells? Trends Parasitol. 20, 275-279 (2004).

43. Araujo, R. \& Cabral, J. P. Fungal Air Quality in Medical Protected Environments "Air Quality" ISBN 978-953-307-131-2, https://doi. org/10.5772/9766 (2010).

44. Martinez, K. F., Rao, C. Y., Burton, N. C. Exposure assessment and analysis for biological agents. Grana, 10.1080/00173130410000794 (2004).

45. Stetzenbach, L. D., Buttner, M. P. \& Cruz, P. Detection and enumeration of airborne biocontaminants. Curr. Opin. Biotechnol, https:// doi.org/10.1016/j.copbio.2004.04.009 (2004).

46. Fenoy, S., Rueda, C., Higes, M., Martín-Hernández, R. \& del Aguila, C. High-level resistance of Nosema ceranae, a parasite of the honeybee, to temperature and desiccation. Appl. Environ. Microbiol, https://doi.org/10.1128/AEM.01025-09 (2009).

47. Sánchez Collado, J. G., Higes, M., Barrio, L., Martín-Hernández, R. Flow cytometry analysis of Nosema species to assess spore viability and longevity Parasitol. Res, https://doi.org/10.1007/s00436-014-3814-z (2014).

48. Bailey, L. Nosema apis in drone honeybees. J. Apic. Res. 11, 171-174 (1972)

49. Bailey, L. The preservation of infective microsporidian spores. J. Invertebr. Pathol. 20, 252-254 (1972).

50. Lotmar, R. Beiträge zur Pathologie des Bienendarmes C. Über den Infektionsverlauf und die Vermehrung des Parasiten Nosema apis (Quantitative Untersuchungen). Landw. Jb. Schweiz. 54, 775-805 (1940).

51. McGowan, J. et al. Viability and infectivity of fresh and cryopreserved Nosema ceranae spores. J. Microbiol. Meth, https://doi. org/10.1016/j.mimet.2016.09.021 (2016).

52. Chu, W. H. \& Jaques, R. P. Factors affecting infectivity of Vairimorpha necatrix (Microsporida: Nosematidae) in Trichoplusia ni (Lepidoptera: Noctuidae). Can. Entomol. 113, 93-102 (1981).

53. Higes, M., Martin, R. \& Meana, A. Nosema ceranae a new microsporidian parasite in honeybees in Europe. J. Invertebr. Pathol. https://doi.org/10.1016/j.jip.2006.02.005 (2006).

54. Paxton, R. J., Klee, J., Korpela, S. \& Fries, I. Nosema ceranae has infected Apis mellifera in Europe since at least 1998 and may be more virulent than Nosema apis. Apidologie, https://doi.org/10.1051/apido:2007037 (2007).

55. Izquierdo, F. et al. Detection of microsporidia in drinking water, wastewater and recreational rivers. Water. Res. 45, 4837-43 (2011).

56. Goodman, L. Form and Function in the Honey Bee (International Bee Research Association, 2003).

57. Fries, I., Granados, R. R. \& Morse, R. A. Intracellular germination of spores of Nosema apis Z. Apidologie 23, 61-70 (1992).

58. de Graaf, D., Raes, H. \& Jacobs, F. J. Spore dimorphism in Nosema apis (Microsporida, Nosematidae) developmental cycle. J. Invertebr. Pathol. 63, 92-94 (1994).

59. Delbac, F. \& Polonais, V. The Microsporidian Polar Tube and Its Role In Invasion. in: Burleigh BA, Soldati-Favre D (eds) 208-220 (Molecular Mechanisms of Parasite Invasion, 2008).

60. Copley, T. R., Giovenazzo, P. \& Jabaji, S. H. Detection of Nosema apis and N. ceranae in honeybee bottom scraps and frass in naturally infected hives. Apidologie. 43, 753-760 (2012).

61. Graystock, P., Goulson, D. \& Hughes, W. O. H. The relationship between managed bees and the prevalence of parasites in bumblebees. Peer. J, https://doi.org/10.7717/peerj.522 (2014).

62. Arneberg, P., Skorping, A., Grenfell, B. \& Read, A. F. Host densities as determinants of abundance in parasite communities. Proc. R. Soc. Lond. B. 265, 1283-1289 (1998).

63. Brown, M. J. F., Loosli, R. \& Schmid-Hempel, P. Condition-dependent expression of virulence in a trypanosome infecting bumblebees. Oikos. 91, 421-427 (2000).

64. Lafferty, K. D. \& Gerber, L. R. Good medicine for conservation biology: the intersection of epidemiology and conservation theory. Conserv. Biol. 16, 593-604 (2002).

65. Mallon, E. B., Brockmann, A. \& Schmid-Hempel, P. Immune response inhibits associative learning in insects. Proc. R. Soc. Lond. B. 270, 2471-2473 (2003).

66. Goulson, D. \& Sparrow, K. Evidence for competition between honeybees and bumblebees; effects on bumblebee worker size. J. Insect. Conserv, https://doi.org/10.1007/s10841-008-9140-y (2009).

67. Foley, K., Fazio, G., Jensen, A. B. \& Hughes, W. O. H. Nutritional limitation and resistance to opportunistic Aspergillus parasites in honey bee larvae. J. Invertebr. Pathol. 111, 68-73 (2012).

68. Elbgami, T., Kunin, W. E., Hughes, W. O. H. \& Biesmeijer, J. C. The effect of proximity to a honeybee apiary on bumblebee colony fitness, development, and performance. Apidologie. 45, 504-513 (2014).

69. Paxton, R. J. Does infection by Nosema ceranae cause "Colony Collapse Disorder" in honey bees (Apis mellifera)? J. Apic. Res, https:// doi.org/10.3896/IBRA.1.49.1.11 (2010).

70. Roberts, K. E. \& Hughes, W. O. H. Immunosenescence and resistance to parasite infection in the honey bee, Apis mellifera. J. Invertebr. Pathol. 121, 1-6 (2014).

71. Fries, I. et al. Standard methods for Nosema research. In: The COLOSS BEEBOOK: Volume II: Standard methods for Apis mellifera pest and pathogen research, Dietemann, V., Ellis, J. D., Neumann, P., eds J. Apic. Res, https://doi.org/10.3896/IBRA.1.52.1.14 (2013).

72. Forsgren, E. \& Fries, I. Comparative virulence of Nosema ceranae and Nosema apis in individual European honey bees. Vet. Parasitol. 170, 212-217 (2010).

73. Killick, K. A. Purification of Dictyostelium discoideum spores by centrifugation in percoll density gradients with retention of morphological and biochemical integrity. Anal. Biochem, https://doi.org/10.1016/0003-2697(81)90449-8 (1981).

74. Stach, A. The use of Hirst volumetric trap, preparation of drums and slides. Advances in Dermatology and Allergology/Post. Derm. Alerg. 4, 246-249 (2003).

75. Galán, C. \& Dominguez-Vilches, E. The capture media in aerobiological sampling. Aerobiologia 13, 155-160 (1997). 
76. Emberlin, J. Aerobiology, aerodynamics and pollen sampling PDiA. Advances in Dermatology and Allergology/Post. Derm. Alerg. 4, 196-199 (2003).

77. Frenguelli, G. Basic microscopy, calculating the field of view, scanning of slides, sources of error. Advances in Dermatology and Allergology/Post. Derm. Alerg. 4, 227-229 (2003).

78. Martin-Hernández, R. et al. Outcome of colonization of Apis mellifera by Nosema ceranae. Appl. Environ. Microbiol., https://doi. org/10.1128/AEM.00270-07 (2007).

\section{Acknowledgements}

Financial support for this work was provided by the Ministry of Science and Higher Education DS-2 and the National Science Centre, Poland (Grant No. 2015/17/BNZ9/03607).

\section{Author Contributions}

G.B., A.S. and M.T. designed the research. G.B. and A.S. conducted the experiments. B.H., T.H.S., W.K., M.K. and M.T. contributed to the project with analytical tools. A.S., B.H., M.K., M.T. and M.C. analysed the data. A.S., B.H., M.K., M.C., G.B. and M.T. wrote the manuscript. All of the authors have read and approved the manuscript.

\section{Additional Information}

Competing Interests: The authors declare no competing interests.

Publisher's note Springer Nature remains neutral with regard to jurisdictional claims in published maps and institutional affiliations.

(c) (i) Open Access This article is licensed under a Creative Commons Attribution 4.0 International License, which permits use, sharing, adaptation, distribution and reproduction in any medium or format, as long as you give appropriate credit to the original author(s) and the source, provide a link to the Creative Commons license, and indicate if changes were made. The images or other third party material in this article are included in the article's Creative Commons license, unless indicated otherwise in a credit line to the material. If material is not included in the article's Creative Commons license and your intended use is not permitted by statutory regulation or exceeds the permitted use, you will need to obtain permission directly from the copyright holder. To view a copy of this license, visit http://creativecommons.org/licenses/by/4.0/.

(C) The Author(s) 2019 